\title{
Advances in cortical modulation of pain
}

This article was published in the following Dove Press journal:

Journal of Pain Research

18 September 2013

Number of times this article has been viewed

\section{Gabriel C Quintero}

Florida State University - Panama, Neuroscience, Republic of Panama; Smithsonian Tropical Research Institute (STRI), Balboa, Republic of Panama
Correspondence: Gabriel C Quintero Florida State University - Panama, 227 Clayton, Ciudad del Saber, Republic of Panama Email gquintero@fsu.edu
Abstract: Pain is an intricate phenomenon composed of not only sensory-discriminative aspects but also of emotional, cognitive, motivational, and affective components. There has been ample evidence for the existence of an extensive cortical network associated with pain processing over the last few decades. This network includes the anterior cingulate cortex, forebrain, insular cortex, ventrolateral orbital cortex, somatosensory cortex, occipital cortex, retrosplenial cortex, motor cortex, and prefrontal cortex. Diverse neurotransmitters participate in the cortical circuits associated with pain processing, including glutamate, gamma-aminobutyric acid, dopamine, and opioids. This work examines recent rodent studies about cortical modulation of pain, mainly at a molecular level.

Keywords: pain, glutamate, glia, cingulate cortex, somatosensory cortex, insular cortex

\section{Introduction}

Despite broad advances in knowledge of the neurobiological basis of pain at the different levels of the central nervous system - periphery, spinal cord circuitry, brain-stem circuitry - there is relatively scarce knowledge about pain circuitry at cortical levels and its behavioral correlates. Different authors have pointed out the importance of exploring the cortical mechanisms of pain. ${ }^{1}$ A review of different methods for studying chronic pain in rodents has been described by other authors, and is out of the scope of the present review. ${ }^{1}$ The present review cites diverse pain models: peripheral nerve injury, formalin inflammatory, formalinconditioned place avoidance, and nerve ligation (peroneal and sciatic). Also, it covers diverse types of pain: neuropathic, inflammatory, esophageal, visceral, and arthritic. On the other hand, an excellent review has pointed out the relevance of the cortical network in pain processing and integrating the medial and lateral pain system (anterior cingulate cortex [ACC], agranular insular cortex [AIC], primary somatosensory [SS] cortex [SI], secondary SS cortex [SII], ventrolateral orbital [VLO] cortex, and motor cortex), and its diverse neurotransmitter composition (opioid, glutamate, gamma-aminobutyric acid [GABA], and dopamine). ${ }^{2}$

The purpose of the present review is to offer an overview of research about molecular aspects of cortical structures involved in the modulation of physiological and pathological pain, and its behavioral correlates at the basic (animal) level. 


\section{Interconnections between cortical}

and other structures involved

in modulation of pain

\section{Descending pathways}

In general, the cortex sends descending projections directly or indirectly to the dorsal horn of the spinal cord and trigeminal nucleus for modulating nociception. ${ }^{3}$ The indirect projections from the cortex to the dorsal horn (spinal or trigeminal) could be mediated by means of three main paths: the first a circuit with the sequence cortex/hypothalamus/periaqueductal gray (PAG)/medulla/dorsal horn; the second a circuit of cortex/ amygdala/PAG/medulla/dorsal horn; and the third a route with the order cortex/PAG/medulla/dorsal horn. ${ }^{3}$ However, there is one indirect projection from the cortex, specifically SII, that goes to the dorsal horn of the spinal cord by means of thalamus relay without mediation of the PAG. ${ }^{2}$

The cortical inputs to the PAG could be direct or indirect. The direct cortical inputs to the PAG arise from the motor cortex and the ACC. The indirect cortical inputs to the PAG arise from the ACC or SII. These indirect cortical inputs consist of three sequences of structures: ACC/amygdala/ PAG, ACC/thalamus/amygdala/PAG, and SII/thalamus/ amygdala/PAG. ${ }^{2}$

The PAG is located in the midbrain, and subsequently sends projections to the medulla related to descending modulation of nociception. ${ }^{4}$ In the medulla, there is a zone named the rostral ventromedial medulla (RVM), which contains among others the nuclei raphe magnus and reticularis gigantocellularis. The RVM projects to the dorsal horn of the spinal cord (directly or indirectly) for increasing or decreasing nociceptive input. ${ }^{5}$ The PAG also sends direct and indirect projections to the spinal cord for inhibiting nociception. ${ }^{6}$ The dorsolateral funiculus (DLF) mediates supraspinal antinociception and RVM sent projections in this tract. ${ }^{7,8}$ Specifically, the descending projections from the RVM establish synaptic interactions in the spinal dorsal horn with interneurons: first-, second-, and third-order neurons that convey nociceptive inputs. $^{9-11}$ The antinociceptive effects of the RVM and PAG on the spinal cord are mediated by means of serotonin, glycine, or GABA neurotransmitters. ${ }^{12,13}$

\section{Ascending pathways}

Inputs related to nociception enter the spinal dorsal horn through primary afferent fibers that cross the spinal cord and synapse onto contralateral transmission neurons. ${ }^{4}$ Next, the fibers from the spinal cord dorsal horn ascend, and could target three different supraspinal structures: the thalamus, the amygdala, and the brain stem (mesencephalic dorsal reticular nucleus, midbrain PAG, and RVM). ${ }^{4}$ The thalamus subsequently sends projections to the cerebral cortex and amygdala; the amygdala, besides receiving projections from the thalamus and the spinal cord, also receives projections from the brain stem. Moreover, the amygdala sends nociceptive-related projections to the cerebral cortex and thalamus. ${ }^{4}$ An illustration describing the main ascending and descending pathways and cortical and subcortical structures involved in pain is portrayed in Figure 1.

\section{Cortical structures involved in pain Anterior cingulate cortex}

The ACC is located in the frontal part of the cingulate cortex, and it surrounds the rostral area of the corpus callosum. It appears to participate in diverse autonomic functions, such as regulating blood pressure and heart rate, and also in rational cognitive functions, such as reward anticipation, decision-making, empathy, impulse control, and emotion. ${ }^{14,15}$ Different studies have shown that this structure is involved in neuropathic pain conditions. ${ }^{16}$ The role of pyramidal neurons of the ACC in nociception has been probed by patch-clamp electrophysiology studies in mice. ${ }^{17}$

Moreover, different studies have shown that the rostral cingulate cortex mediates the aversive component of pain. ${ }^{18,19}$ A rodent study reported that rostral but not caudal cingulate cortex activity is necessary for the perception of the aversive component of inflammatory pain. That study employed formalin-conditioned place avoidance in rats; in addition, disruption of the rostral cingulate cortex did not alter acute pain-related behavior (eg, licking or lifting the paw). ${ }^{19}$ A similar study in rats showed that the rostral cingulate cortex also mediates the aversive component of long-lasting pain, such as neuropathic pain. ${ }^{18}$

\section{Adenylyl cyclases}

Adenylyl cyclase 1 (AC1) and AC8 are $\mathrm{Ca}^{2+} /$ calmodulinstimulated adenylyl cyclases highly expressed in the ACC and insular cortex that couple $N$-methyl-D-aspartate (NMDA) receptor-induced cytosolic $\mathrm{Ca}^{2+}$ increases to cyclic adenosine monophosphate signaling pathways. ${ }^{20}$ Specifically, calcium-stimulated $\mathrm{AC} 1$ has been pointed out as a relevant molecular target for nerve injury-induced synaptic changes in the ACC. ${ }^{16}$ Possible treatment based on drug screening has revealed an AC1-specific inhibitor, NB001, as a very effective analgesic in animal models of neuropathic pain, and denoting absence of side effects when administered by means of intraperitoneal or oral routes. ${ }^{16}$ 


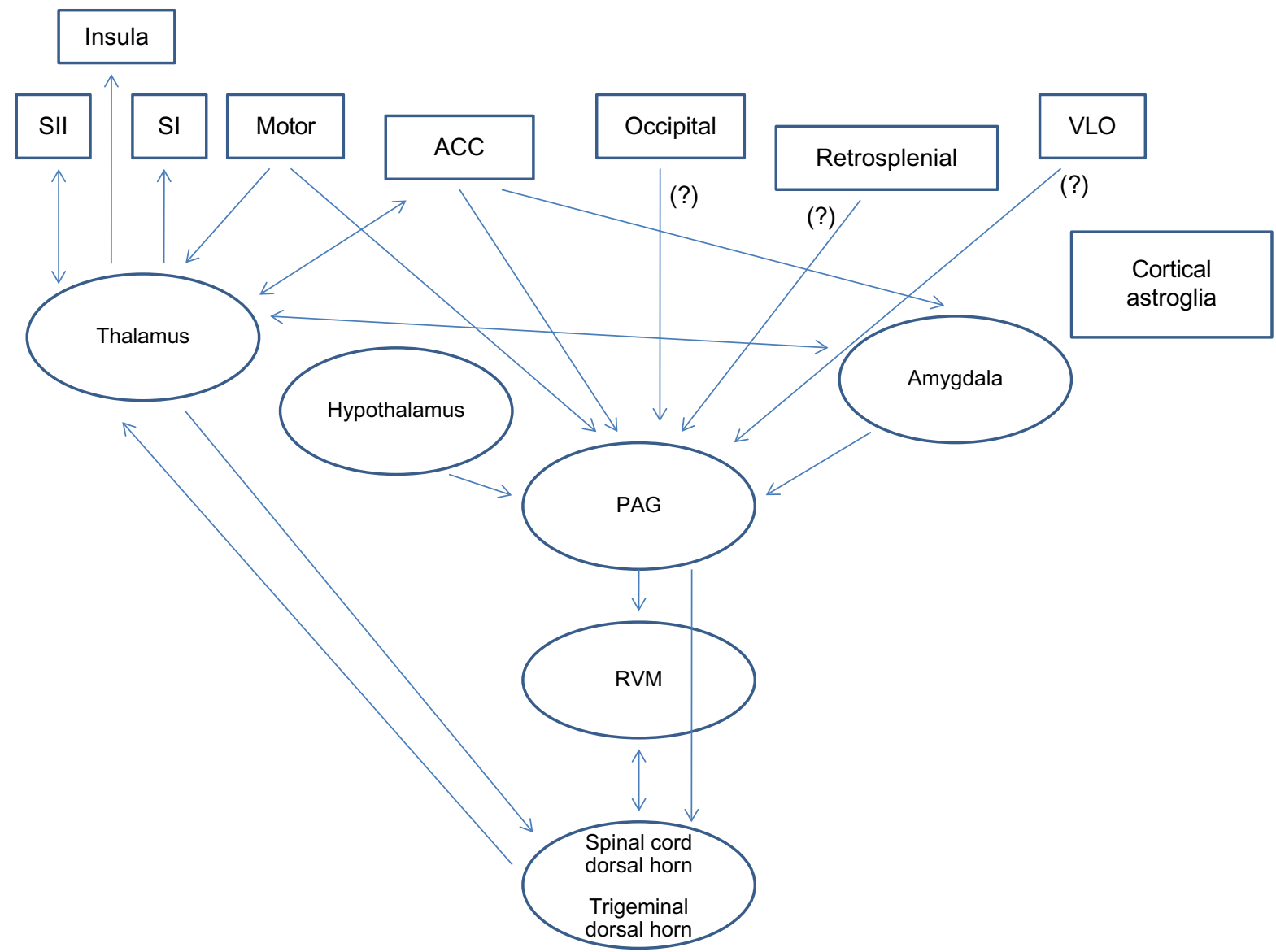

Figure I General description of the main cortical and subcortical structures and the respective ascending and descending interconnections, based on the most recent research reports.

Note: (?), Possibly projections from these structures.

Abbreviations: ACC, anterior cingulate cortex; PAG, periaqueductal gray; RVM, rostral ventromedial medulla; SI, primary somatosensory cortex; SIl, secondary somatosensory cortex; VLO, ventrolateral orbital cortex.

Moreover, another study also reported that $\mathrm{AC} 1$ and $\mathrm{AC} 8$ at the level of the ACC have been linked to nerve injury and inflammatory pain, and proposed as possible therapeutic targets. ${ }^{21}$ Specifically, a mutant-mice study demonstrated that disruption of $A C 1$ and/or $A C 8$ genes reduced inflammatory pain levels, and disruption of $A C 1$ and $A C 8$ (but not $A C 8$ alone) genes reduced allodynia. ${ }^{21}$

\section{Astrocytic markers and proinflammatory cytokines}

Another study reported that the affective component of pain, evaluated by means of formalin-conditioned place avoidance in rats was correlated with an increase in messenger RNA (mRNA) of astrocytic markers (glial fibrillary acidic protein and S100B), and proinflammatory cytokines (interleukin [IL]-1 beta and tumor necrosis factor alpha) in the ACC; the protein levels of glial fibrillary acidic protein, IL-1 beta, and tumor necrosis factor alpha were also enhanced in the ACC. These results showed for the first time that astrocytes and proinflammatory cytokines are associated with the processing of pain-related aversion and may be crucial players in the affective dimension of pain in rats. ${ }^{22}$

\section{NMDA-receptor pathways}

Different studies have shown the relationship between the increase in the antagonism of the NR2B subunit of ACC's NMDA receptors and the level of tonic pain. As an illustration, a study in mutant mice demonstrated that overexpression of the NR2B subunit of NMDA receptors in the ACC correlated with enhanced nociceptive responses in inflammatory pain models (formalin test and complete Freund's adjuvant [CFA]). The formalin test showed enhanced second-phase pain response, and the CFA showed enhanced mechanical allodynia. ${ }^{23}$ Moreover, another complementary study of the same group proved that tissue inflammation induces upregulation of NR2B at the level of the ACC and enhanced NMDA receptor-mediated response. ${ }^{24}$ Moreover, complementary studies with the pharmacological antagonism of NR2B at the level of the ACC (drugs Ro 25-6981 and 
Ro 63-1908) have shown a reduction of tonic pain in male and female rodents. ${ }^{24,25}$

\section{Protein kinase pathways}

Some researchers have reported protein kinase (PK) M zeta at the level of the ACC as a potential treatment target for tonic pain conditions. ${ }^{26,27}$ PKM zeta is an enzyme that is responsible for maintaining long-term memories in the brain, specifically the late phase of long-term potentiation (LTP). ${ }^{28,29}$ PKM zeta is an independent catalytic domain of PKC zeta and lacks an autoinhibitory regulatory domain of the full-length PKC zeta, thus PKM zeta is persistently active, without the need of a second messenger. The promoter of full-length PKC zeta is largely inactive in the forebrain, and so PKM zeta is the dominant form in the forebrain and the only PKM that is translated from its own mRNA. ${ }^{30} \mathrm{Li}$ et al reported that inhibiting PKM zeta by zeta-pseudosubstrate inhibitory peptide produces analgesic effects in animal models of chronic pain. ${ }^{26}$ Moreover, Li et al also proposed that targeting PKM zeta or its up- or downstream signaling proteins in the ACC may provide novel clinical treatment for chronic pain. ${ }^{27}$

However, recent studies have questioned the relevance of PKM zeta and PKC zeta in the maintenance of LTP and memory. ${ }^{31,32}$ For example, a study showed that transgenic knockout mice (conventional and conditional) lacking PKM zeta and PKC zeta displayed intact synaptic transmission and LTP in hippocampus synapses (Schaffer collateralCA1) and intact learning and memory in tasks relying on hippocampal functioning. Nevertheless, zeta-inhibitory peptide administration to both knockout mice (PKM zeta and PKC zeta) annuls LTP, suggesting that the effects of zeta-inhibitory peptide are separated from PKM zeta. ${ }^{31}$ This finding in learning and memory processes also questions the relevance of PKM zeta in the maintenance of chronic pain conditions, which are similar to LTP and memory processes, and suggests more exploration of the role of PKM zeta and $\mathrm{PKC}$ zeta in chronic pain conditions is needed. ${ }^{33}$

\section{ACC synapses}

Recent research has elucidated the synaptic mechanism of transmitter release at the ACC synapse. As is already known, peripheral inflammation and nerve injury enhance excitatory synaptic transmission in the ACC synapses; besides this, the exact mechanism of presynaptic quantal release in the ACC after chronic pain has been elucidated. Specifically, the analysis showed that the probability of transmitter release and quantity of vesicles were augmented in a mouse model of peripheral inflammation, whereas only the probability of transmitter release was increased in a mouse model of neuropathic pain. ${ }^{34}$

\section{Esophageal pain}

The ACC has been linked to the processing of esophageal pain. ${ }^{35}$ Early exposure to esophageal pain (early life esophageal acid reflux) at p7-p14 has different effects compared to acute adult exposure (p60) at the level of the ACC. Specifically, this study found increased expression of the NR1 and NR2A subunits of NMDA receptors, and postsynaptic density 95 (PSD)-95, measured 6 weeks after early postnatal exposure. However, this change was temporary and limited to NMDA-receptor subunits under adult acute exposure. Interestingly, if adult exposure was preceded by neonatal exposure, these changes were even stronger. ${ }^{35}$

At a more molecular level of examination, esophageal acid exposure induced $\mathrm{Ca}^{2+} /$ calmodulin-dependent PK II (CaMKII)-mediated phosphorylation of serine 1303 residue of the NR2B subunit. This molecular alteration in the ACC might mediate sensitization of patients with acid-induced esophageal disorders. ${ }^{35}$

\section{Forebrain}

The forebrain is the most rostral area of the brain; it is composed of the thalamus, hypothalamus, and cerebrum. The forebrain regulates diverse functions like receiving and processing sensory information, thinking, perceiving, producing and comprehending language, and controlling motor function.

\section{Calcium calmodulin kinase pathways}

Several research reports have focused attention on the forebrain area as a target to explore pain relief. In particular, related studies in mutant mice have shown that manipulations of CaMKII at the level of the forebrain influence persistent pain response. ${ }^{36,37} \mathrm{CaMKII}$ has been linked among others to LTP: the neurobiological process of strengthening active synapses related to memory processes. ${ }^{38} \mathrm{CaMKII}$ phosphorylates $\alpha$-amino-3-hydroxy-5-methyl-4-isoxazolepropionic acid (AMPA) receptors at the P2 serine 831 sites. This phosphorylation increases channel conductance of glutamate A1 subunits of AMPA receptors, which permits AMPA receptors to be more sensitive than normal during $\mathrm{LTP}^{38}$ Increased AMPA-receptor sensitivity leads to an augmentation of synaptic strength. ${ }^{39}$ In effect, a study showed that overexpression of CaMKII in the forebrain reduced mechanical allodynia and thermal hyperalgesia in a CFA model. ${ }^{36}$ 
Moreover, the study suggested that the analgesic effects could be mediated by means of disruption of long-term depression without secondary effects.

\section{Insular cortex}

The insular cortex (insula) is an area of the cerebral cortex folded within the lateral Sylvian fissure. The insular cortex is involved in diverse functions, such as consciousness, emotion, and regulation of the body's homeostasis. Other functions comprehend perception, motor control, self-awareness, and cognitive functioning. More related to nociception, the insular cortex is the area where the degree of pain sensation is judged; it also relates to pain imagination when looking at pictures of painful events. ${ }^{40,41}$

\section{NMDA pathways}

Some studies have revealed the relevance of the insular cortex in the modulation of tonic pain conditions. ${ }^{23}$ Specifically, studies in mutant mice demonstrated that overexpression of the NR2B subunits of NMDA receptors at the level of the insular cortex correlated with enhanced nociceptive responses in inflammatory pain models (formalin test and CFA). In that study, the formalin test proved enhanced second-phase pain response, and the CFA showed enhanced mechanical allodynia. ${ }^{23}$

\section{Morphine modulation}

Another study has shown that morphine infusion in the rostral AIC (RAIC) reduces the firing of dorsal horn neurons related to pain, and also induces analgesia in the formalin test; this reduction is reversed by naloxone (opioid antagonist) treatment. ${ }^{42}$

\section{GABA pathways}

Enhancing GABA neurotransmission at the level of the RAIC can reduce pain levels by means of enhancing descending inhibition upon spinal nociceptive neurons; nevertheless, specific agonism of $\mathrm{GABA}_{\mathrm{B}}$ receptors induces an increase in nociception by means of circuitry with the amygdala. ${ }^{43}$ Agonism of $\mathrm{D}_{2}$ by means of $R(-)$-2,10,11-trihydroxy- $N$ propyl-noraporphine hydrobromide and antagonism of $\mathrm{D}_{1}$ (SCH-23390) at the level of the RAIC induces antinociception, decrease in the autotomy score, and a delay in the onset of pain in the neuropathic pain model induced by denervation. ${ }^{44}$

In general, there is consensus that the insular cortex mediates nociception by means of opioid, GABA, and dopamine systems. ${ }^{42-49}$ Another series of studies has drawn attention to the analgesic role of RAIC in rat nociception. The RAIC has broad cortical connectivity with the ACC, contralateral RAIC, and orbital and infralimbic cortices. It has been proposed that projections from the medial thalamic nuclei to the RAIC are related to motivational/affective components of pain. Moreover, projections from the RAIC to the ventral forebrain contribute to sensorimotor integration of pain, and descending projections from the RAIC to the brain stem are related to descending inhibitory control of pain. ${ }^{50}$

\section{Ventrolateral orbital cortex}

The VLO cortex is part of the prefrontal cortex (PFC); the PFC is located in the most rostral area of the frontal lobes. The VLO cortex has been linked to pain, memory, and emotion; moreover, it is suggested that it is involved in the processing of both pain sensation and pain effect. ${ }^{51-54}$

\section{Dopamine pathways}

The VLO cortex is another brain zone that has been indicated as a modulator of nociceptive responses. ${ }^{55}$ The application of $\mathrm{D}_{1}$ and $\mathrm{D}_{2}$ agonists or antagonists at the VLO level could modulate differently persistent inflammatory pain responses (formalin test) in rats. Specifically, $\mathrm{D}_{1}+\mathrm{D}_{2}$ agonism (apomorphine treatment) induced reduction of late-phase nociceptive behavior. ${ }^{55}$ This analgesic effect was antagonized by $\mathrm{D}_{2}$-selective antagonism (raclopride), but not by $\mathrm{D}_{1}$-selective antagonism (SCH-23390). Selective agonism of $\mathrm{D}_{2}$ receptors (quinpirole) in the same VLO area also mimicked apomorphine antinociceptive effects, and it was also reversed by raclopride $\mathrm{D}_{1}$ agonism (SKF-38393). However, the $\mathrm{D}_{1}$-selective antagonism (SCH-23390) dosedependently reduced nociceptive behavior. ${ }^{55}$ This means that $\mathrm{D}_{2}$ receptors mediate dopamine-induced antinociception and that $\mathrm{D}_{1}$ receptors mediate dopamine-induced nociception, and blocking $\mathrm{D}_{1}$ receptors could decrease nociception.

An explanation of this difference in the effects of $\mathrm{D}_{2}$ versus $D_{1}$ receptors is that $D_{2}$ is an inhibitory G-proteincoupled receptor, but $\mathrm{D}_{1}$ is an excitatory G-protein-coupled receptor. Therefore, activation of $\mathrm{D}_{2}$ induces depression of neural activity by means of hyperpolarization, but activation of $\mathrm{D}_{1}$ induces excitation of neural activity by means of depolarization. . $^{3,56,57}$

\section{Opioid modulation}

Similarly, parallel studies in rats have shown that injection of anesthetic or electrical stimulation of the orbital cortex reduces the thresholds of different reflexes (nociceptive, tail flick, and jaw open). ${ }^{54,58,59}$ Moreover, pharmacological 
treatment of the VLO cortex with opioids (morphine), lidocaine, or GABA reduced levels of inflammatory pain in rodents, inhibited the tail-flick reflex and formalin-evoked c-Fos expression in the spinal cord, and suppressed thermal tactile allodynia and hyperalgesia. ${ }^{47,60,61}$ These results provide evidence for the hypothesis that opioid-induced antinociception in the VLO cortex might be produced by opioids via the $\mu$-opioid receptor subtype 1 , which exerts inhibitory effects on GABAergic inhibitory neurons, resulting in disinhibition of VLO cortex projection neurons and leading to activation of the VLO-PAG brain-stem descending pain-control system to depress the nociceptive inputs at the trigeminal/spinal cord level. A similar disinhibitory effect has been found in the RVM. ${ }^{61}$

In summary, there appears to be a feedback pathway between the spinal cord/trigeminal nucleus and submedius/ $\mathrm{VLO} / \mathrm{PAG}$ that is regulated by opioidergic, dopaminergic, and GABAergic components and interactive mechanisms.

\section{PAG-on/off cells}

Some authors have proposed that VLO regulation of the descending pathway that inhibits nociception is mediated through PAG-on/off cells. ${ }^{2}$ In effect, these authors have shown that VLO neurons showed excitatory or inhibitory responses after injection of glutamate into the nucleus submedius, and these responses were similar to those of noxious stimuli. ${ }^{2}$ As a reference, the nucleus submedius is a thalamic structure separated from the ventromedial part of the mediodorsal nucleus of the thalamus by the internal medullary lamina. ${ }^{62}$ All these data suggest that the combined activity of the nucleus submedius, VLO cortex, and PAG can modulate nociceptive inputs at the trigeminal/spinal cord levels.

\section{Somatosensory cortex}

The SS cortex is located in the postcentral gyrus of the parietal lobe. It is an area that processes inputs related to the sensory system of touch, nociception, temperature, and proprioception. ${ }^{63}$

\section{Electrical stimulation}

Few research reports have described the involvement of the $\mathrm{SS}$ cortex in the modulation of tonic pain responses. Specifically, the SI and SII have been linked to processing sensorydiscriminative aspects of pain. ${ }^{63}$ Also, it has been reported that electrical stimulation of SII reduced nociceptive behaviors of the formalin test. ${ }^{64,65}$ On the other hand, a complementary study showed that electrical stimulation of the SII in combination with 7-nitroindazole reduced the number of c-Fos-positive cells in the spinal dorsal horn in conscious rats. ${ }^{65}$ A similar study reported that electrical stimulation of the SII also reduced the number of c-Fos-positive cells in the trigeminal dorsal horn induced by injection of formalin into the lower lip, but electrical stimulation of the SI failed to have this effect. ${ }^{66}$

\section{Glutamatergic modulation}

A study indicates that glutamate metabotropic receptors (GRM) and opioid receptors may be involved in the modulation of acute and inflammatory pain in the SI and SII. Moreover, expression of mRNA of GRM type 3 was significantly increased in the SI and SII cortical areas in monoarthritic rats (average increases of 50\%-75\%) ${ }^{67}$

\section{Pituitary adenylate cyclase-activating polypeptide-38 pathway}

Another study has pointed to the relevance of pituitary adenylate cyclase-activating polypeptide (PACAP) 38 at the level of the SS in the modulation of visceral and inflammatory pain. As a reference, PACAP 38 is a neuropeptide of the vasoactive intestinal polypeptide-secreting glucagon family. PACAP receptors are expressed in different brain regions, including the cerebellum. ${ }^{68}$ Specifically, a study showed a correlation between the reduction of visceral and inflammatory pain in PACAP-38 knockout mice and c-Fos expression in the SS of rats. ${ }^{69}$ This suggests that there exist potential inhibitory mechanisms mediated by the SS that are silenced by the presence of PACAP activation. ${ }^{69}$

\section{Adrenergic modulation}

Moreover, different research has shown the significance of alpha adrenoceptors at the level of the sensorimotor cortex in the control of inflammatory pain. The adrenoceptors (adrenergic receptors) are a class of metabotropic G-protein-coupled receptors that is targeted by the catecholamines, especially noradrenaline (norepinephrine) and adrenaline (epinephrine). $A_{1}$ is a member of the $G$-protein-coupled receptors superfamily. Upon activation, a heterotrimeric $\mathrm{G}$ protein, $\mathrm{Gq}$, activates phospholipase C. Subsequently, the phospholipase C cleaves phosphatidylinositol 4, 5-biphosphate, which in turn causes an increase in inositol triphosphate and diacylglycerol. The former interacts with calcium channels of the endoplasmic and sarcoplasmic reticulum, thus modifying the calcium content in a cell. This triggers all other effects. ${ }^{70}$ On the other hand, adenosine type 2 receptors, among other functions, are linked to negative feedback in the neuronal synapses causing 
presynaptic inhibition of noradrenalin release in the central nervous system. ${ }^{70}$

In particular, a study has examined the effects of alpha-1 adrenoceptors in adenosine analgesia in the formalin pain behavior of male CD1 mice. ${ }^{71}$ That study used type 1 or type $2 \mathrm{~A}$ receptor agonists, such as $\mathrm{N}(6)$-cyclopentyladenosine and 2-p-(2-carboxyethyl)-phenylethylamino- $5^{\prime}-\mathrm{N}$ ethylcarboxamidoadenosine hydrochloride (CGS21680). In the behavioral experiment, alpha-1 adrenoceptors were blocked by an alpha-1 adrenoceptor antagonist - prazosin. Alpha-1 adrenoceptor density was depressed in the ipsilateral and contralateral sensorimotor cortex during the late phase of the formalin test. The depression of alpha-1 adrenoceptors may suggest the development of hypersensitivity in a given structure, and this was antagonized by CGS21680, suggesting the role of adenosine type $2 \mathrm{~A}$ receptors in the control of inflammatory formalin pain. ${ }^{71}$

\section{Occipital cortex}

The occipital cortex is the part of the cerebral cortex that is located in the back of the forebrain. The occipital cortex is the visual processing center of the mammalian brain, and contains most of the anatomical region of the visual cortex. ${ }^{72}$

\section{Electrical stimulation}

A fascinating study demonstrated connections between the occipital cortex and structures involved in pain-descending inhibitory mechanisms. ${ }^{72}$ That rat study demonstrated that electrical stimulation of the occipital cortex induces reduction of tonic inflammatory (formalin test) and phasic pain (tailflick test). ${ }^{72}$ Moreover, the study proved that the inhibitory effect was mediated by means of the dorsolateral funiculus. Furthermore, application of a glutamate agonist in the occipital cortex induced similar analgesic effects. Electrical stimulation did not induce motor-coordination side effects, based on the rotarod test, or epileptiform changes, according to electroencephalography. ${ }^{72}$

\section{Retrosplenial cortex}

The retrosplenial cortex is the most caudal part of the cingulate gyrus. It has been linked to such cognitive functions as episodic memory, navigation, imagination, and planning for the future. ${ }^{73}$

\section{Electrical stimulation}

Retrosplenial cortex activity has also been linked to levels of phasic and tonic inflammatory pain. ${ }^{72}$ A study in rats demonstrated connections between the retrosplenial cor- tex and structures involved in pain-descending inhibitory mechanisms; electrical stimulation of the retrosplenial cortex induced reduction of tonic inflammatory (formalin test) and phasic pain (tail-flick test). ${ }^{72}$ Moreover, this study demonstrated that the inhibitory effect is mediated by the dorsolateral funiculus. Also, the application of a glutamate agonist in the retrosplenial cortex induces pain relief. Electrical stimulation did not induce motor-coordination side effects, based on the rotarod test, or epileptiform changes, according to electroencephalography. ${ }^{72}$

\section{Motor cortex}

The motor cortex is the part of the cerebral cortex located in the frontal lobe, anterior to the central fissure of Rolando. The functions of the motor cortex are related to sensorimotor integration, control of voluntary movements, and processing of motor-related information. ${ }^{74}$

\section{Glutamatergic modulation}

One study has reported alterations in mRNA levels of GRM type 3 in the cortex of monoarthritic rats, suggesting involvement of the glutamatergic system. ${ }^{67}$ The mRNA levels of GRM types 1, 4, and 7 did not change in monoarthritic rats at 2, 4, and 14 days of the disease. The mRNA of GRM type 3 increased in all time points. The increase in the cerebral cortex was found bilaterally in layers IV/V of the motor cortex, 1ry somatosensory, and 2ry somatosensory cortices, and contralaterally in the cingulate cortex. ${ }^{67}$ According to the authors, this increase in mRNA of GRM type 3 in motor, somatosensory, and limbic cortices could be related to a central mechanism that counteracts the nociceptive information from the inflamed paw and the disrupted motor behavior of these rats. Also, alteration in the activity of the cingulum could be linked to the motivation and affective elements of nociception. ${ }^{67}$

\section{Motor-cortex stimulation}

A recent study proved that cortical stimulation of the motor cortex increases the nociceptive threshold of naïve conscious rats by means of opioid participation. Moreover, a complementary study from the same group showed that transdural stimulation of the motor cortex in naïve rats induces inhibition of thalamic sensory neurons of ventral posterolateral nuclei and the centromedian-parafascicular complex, and disinhibition of neurons in the PAG, inducing antinociception. ${ }^{75}$

A different rat study evaluated the effect of transdural motor-cortex stimulation (MCS) on neuropathic pain (chronic constriction injury of the sciatic nerve); it was reported that MCS reverts neuropathic pain by means of 
activation of the limbic system and the descending inhibitory systems, which include the spinal cord dorsal horn, thalamus (ventral posterior lateral and medial nuclei), PAG, ACC, and the central and basolateral amygdaloid nuclei. ${ }^{76}$

\section{Prefrontal cortex}

The PFC is an area of the forebrain located in the anterior part of the frontal lobes, rostral to the motor and premotor areas. Some authors have described the relevance of PFC activity in the modulation of pain. ${ }^{77}$

\section{DNA methylation}

A rodent study described the relationship between epigenetic effects at the level of the PFC and chronic pain conditions. ${ }^{77}$ Specifically, DNA methylation in the genes of the PFC might mediate the pathologies associated with chronic pain. The study showed that after 5-6 months of peripheral nerve injury, the mice experienced a reduction of DNA methylation in the PFC and the amygdala. Moreover, interventions that alleviated neuropathic pain in these mice, including a rich and more stimulating environment, were accompanied by increases in DNA methylation in both areas. These results suggest that exploration of changes in DNA methylation at the level of the PFC for alleviating chronic pain is needed. ${ }^{77}$

\section{Role of cortical glial cells in pain}

Recent studies have illustrated the significance of glial cells in pain modulation. Glial cells, or neuroglia, are nonneuronal cells that maintain homeostasis, form myelin, and provide support and protection for neurons in the brain and in other parts of the nervous system. ${ }^{78}$

Although glial cells have been reported to modulate pain at both cortical and subcortical levels, the reports on glial cell cortical modulation remain controversial. ${ }^{79-83}$

\section{Microglial activation}

A recent study by Zhuo et al demonstrated the lack of cortical microglial activation during neuropathic pain states. However, they found activation of microglia at spinal levels. ${ }^{84}$ Changes associated with microglial activation include variations in microglia morphology: hypertrophy, thickened and retracted processes, and proliferation of microglia. Moreover, other changes include an increase of immune surface antigens (Toll-like receptor 4, cluster of differentiation molecule 44, major histocompatibility complex II) and an increase in the release of cytotoxic and neurotrophic molecules (phosphorylation of p38 mitogen-activated protein kinases and steroid-receptor coactivator Lyn family of kinases). ${ }^{85-87}$
Also, the pattern of microglial activation was characterized by an early activation of microglia (microgliosis) during the initial phase of neuropathic pain, and a subsequent second phase of astrogliosis activation. Astrogliosis is an abnormal increase in the number of astrocytes due to destruction of nearby neurons. It has therefore been suggested that microglia could be important for the initiation of neuropathic pain, and astrocytes for its maintenance. ${ }^{88,89}$

Further, rigorous efforts in exploring glial activation subsequent to nerve injury, by means of a common peroneal nerve-ligation model, and using transgenic mice with green fluorescence protein-labeled microglia, showed activation of spinal but not supraspinal levels. ${ }^{90}$ Specifically, that study showed a lack of microglial activation in such supraspinal regions as the ACC, PFC, SI, SII, insular cortex, amygdala, hippocampus, PAG, and RVM.

\section{Astroglial activation}

Other studies by different groups support astrogliosis and similar changes in supraspinal structures after nerve damage. ${ }^{81,91}$ Specifically, one study supported astrogliosis in the ACC after sciatic nerve ligation, and this astrogliosis was correlated with anxiety-like behaviors mediated by alterations in the delta-opioid system. ${ }^{81}$ Moreover, another study by Giordano et al reported that 1 week after sparing nerve injury, infralimbic and prelimbic cortices displayed overexpression of different caspases in microglia (caspase 3) and astrocytes (caspase 1), complemented by upregulation of AMPA receptors in microglia. ${ }^{91}$ Furthermore, infusion of a pan-caspase inhibitor into the prelimbic and infralimbic cortices decreased mechanical allodynia. Other changes in neurons, such as upregulation of IL-1 receptor 1, transient receptor potential cation channel subfamily $\mathrm{V}$ member 1 (TRPV1), and vesicular glutamate transporter 1 in glutamatergic neurons, were also observed. This study suggests that spared nerve injury triggers both TRPV1-dependent and independent glutamate and caspase-mediated cross talk among infralimbic and prelimbic cortical neurons and glia, which either participates or counteracts pain. ${ }^{91}$

A study explored the role of glial cells and proinflammatory cytokines at the level of the ACC in pain affect. ${ }^{22}$ ACC activity has been linked to processing of affective components of pain. ${ }^{18,19}$ Specifically, the question of whether formalin-conditioned placed avoidance induces changes in astrocytes and proinflammatory cytokines levels in the ACC was explored. Formalin-conditioned placed avoidance induced marked aversion-like behaviors in rodents. Similarly, a considerable augmentation of mRNA 
of astrocytic markers and proinflammatory cytokines was observed in the ACC. This was the first evidence of glia (astrocytes) and proinflammatory cytokines linked to the processing of pain-related aversion and affective component of pain. ${ }^{22}$

\section{Discussion}

Compared to a previous broad review about cortical modulation of pain by Xie et al, the present review includes an updated description of the aspects detailed in the next parragraphs. $^{2}$

PKM zeta and PKC zeta are not necessarily involved in chronic pain conditions, based on related studies on memory, learning, and LTP in mutant mice lacking PKM zeta or PKC zeta. $^{31,32}$ Because it has previously been proposed that chronic pain conditions were similar to learning, memory, and LTP processes, even in the mediation of PKM zeta and PKC zeta in those processes, then it is questioned that PKM zeta and PKC zeta would also be necessary for the establishment and maintenance of chronic pain conditions. ${ }^{33}$

Epigenetic changes at the level of the PFC, such as DNA methylation, have been linked to conditions that induce or alleviate chronic neuropathic pain. ${ }^{77}$ Specifically, after 6 months of induction of neuropathic pain, there is a decrease in the DNA methylation of the PFC and amygdala. On the other hand, alleviation of chronic pain by means of such interventions as enrichment of the environment reduce pain and reverse (increase) the DNA methylation of the PFC. ${ }^{77}$

MCS has been suggested as treatment for patients with refractory pain; however, the brain mechanism of the antinociceptive effects was not clear. A recent paper cleared up this point, and reported that MCS decreases the activity of sensory neurons of the thalamus, and increases the activity of PAG neurons, activating the descending mechanism for inhibition of pain. $^{75}$

$\mathrm{AC}$ at the level of the ACC has been proposed previously as potential treatment of neuropathic pain, and as an alternative to treatments that focus on the spinal cord or peripheral levels of the nervous system. ${ }^{92,93}$ A recent rodent study proposed NB001, a specific inhibitor of AC1 over other AC isoforms, as a potential treatment for neuropathic pain. ${ }^{16}$ Moreover, this study employed oral and intraperitoneal administration of NB001, and did not find side effects or toxicity based on different behavioral paradigms and toxicity assays. This report has already been addressed by a more recent and specific review about $\mathrm{AC}$ and animal models of chronic pain. ${ }^{94}$

The inclusion of sex differences in pain studies has been proposed by some authors. ${ }^{95-97}$ The present review introduces research on rats that compared the antagonism of NMDA's NR2B subunit of the ACC on inflammatory and phasic pain models. ${ }^{25}$ Based on this study, antagonism of the NMDA receptors at the level of the ACC is able to decrease inflammatory pain in both sexes.

Studies by different groups support astrogliosis and similar changes in supraspinal structures after nerve damage. ${ }^{81,91}$ Moreover, another study compared the activation of microglial cells in neuropathic pain conditions (eg, common peroneal nerve ligation) between the spinal cord and supraspinal sites (ACC, PFC, SI, SII, insular cortex, and other subcortical structures). ${ }^{90}$ Activation of microglial cells in the spinal cord, but not in the supraspinal structures, including the cerebral cortex, was found. ${ }^{90}$ This difference has been described in a very recent review. ${ }^{84}$ However, the present review adds research about the activation and the relationship of astrocytes and cytokines at the level of the ACC with the processing of pain-related aversion, and its potential link with an affective dimension of pain. ${ }^{22}$

This review also added a study that contrasted the agonism and antagonism of different dopamine-receptor types $-\mathrm{D}_{1}$ and $\mathrm{D}_{2}-$ at the level of the VLO cortex on inflammatory pain (formalin test). ${ }^{55}$ It was found that agonism of $\mathrm{D}_{2}$ or $\mathrm{D}_{1}+\mathrm{D}_{2}$ receptors decreased the level of inflammatory pain in the late phase of the formalin test. Moreover, agonism of $\mathrm{D}_{1}$ receptors is able to reverse antinociception induced by $\mathrm{D}_{2}$ agonism. This suggests that $\mathrm{D}_{2}$ receptors mediate antinociception and that $\mathrm{D}_{1}$ receptors mediate nociception. ${ }^{55}$ Therefore, agonism of $D_{2}$ receptors or antagonism of $D_{1}$ receptors at the level of the VLO cortex could be an alternative for exploring analgesics for inflammatory pain.

The present review also introduced an unexplored topic about the relationship of ACC and esophageal pain. ${ }^{35}$ It was found that the earlier the exposure to esophageal acid reflux, the stronger the effects on protein levels of the ACC. Specifically, an earlier exposure (p7-p14 stage) induces a marked augmentation of NMDA-receptor subunits (NR1 and NR2A) and an increase of PSD-95 protein levels in the ACC, compared to later exposure (p60 stage); later exposure only leads to a temporary increase of NMDA subunits. Hence, it is now proposed that the long-term effects of esophageal acid exposure during the early stage of life, such as sensitization, could be explained by plastic changes in the rostral cingulate cortex, such as an increase in NMDA-receptor subunits and PSD-95 protein. ${ }^{35}$

Furthermore, another advance in the field of pain is that the rostral cingulate cortex not only mediates the aversive component of acute inflammatory pain but also mediates the 
aversive component of other types of pain that are long-lasting and combined with nerve damage (eg, neuropathic pain). ${ }^{18,19}$ Finally, other new cortical structures that could modulate tonic inflammatory and phasic pain are the occipital and retrosplenial cortices, by means of activation of the descending tract of the dorsolateral funiculus. ${ }^{72}$

\section{Conclusion}

In conclusion, numerous rodent studies have demonstrated that the central nervous system contains an extensive cortical network associated with pain processing that includes the ACC, forebrain, insular cortex, VLO cortex, SS cortex, occipital cortex, retrosplenial cortex, motor cortex, and prefrontal cortex. Moreover, an ample group of neurotransmitters and chemical messengers including opioids, glutamate, GABA, and dopamine are involved in the modulation of pain by these cortical structures. Glial cells also take a relevant role in the modulation of cortical activity related to the experience of pain.

Some of the more recent studies about cortex and pain suggest that PKM zeta and PKC zeta are not necessarily involved in chronic pain conditions, and more research is necessary to elucidate the specificity or relevance of PKM zeta and PKC zeta on the different types of pain conditions. On the other hand, epigenetic changes, such as DNA methylation at the level of the PFC, could be linked to the maintenance of chronic neuropathic pain, and therapeutic conditions that reduce pain could also reverse (increase) DNA-methylation changes. Moreover, MCS induces analgesia by means of the inhibition of thalamic sensory neurons and the excitation of PAG neurons, inducing then the descending mechanisms of pain inhibition. On the other hand, supraspinal activation of glial cells, such as astrocytes and microglia, is not limited to nociceptive aspects of pain, as has been previously described. Astrocytes and proinflammatory cytokines at the level of the ACC can also be linked to the processing of pain-related aversion. Agonism of $\mathrm{D}_{2}$ receptors or antagonism of $\mathrm{D}_{1}$ receptors at the level of the VLO cortex could be an alternative for exploring inflammatory pain analgesics. Furthermore, the long-term effects of esophageal acid exposure during the early stage of life could be explained by plastic changes in the rostral cingulate cortex, such as an increase in NMDA-receptor subunits and PSD-95. The rostral ACC mediates not only the negative affective component of inflammatory pain but also the aversive component of chronic spontaneous pain arising from nerve injury, based on recent research. Finally, electrical stimulation of the occipital and retrosplenial cortices can modulate tonic inflammatory and phasic pain.

\section{Limitations}

It is necessary to consider that research based on rodent models has some limitations. An example of these limitations is a deficit in face validity: animal models sometimes do not measure or reflect what they are supposed to evaluate. Some examples of rodent-pain models that have been questioned on face validity are nerve ligation (peripheral nerve injury), acetic acid writhing test, orofacial injection of formalin, and intra-articular injection of CFA. ${ }^{98-101}$

Another limitation of rodent models is the discrepancy between rodent models and human conditions in the period between induction of a lesion and the time of testing an analgesic. This period tends to be shorter in rodent models compared to the equivalent human pain condition (eg, osteoarthritis). ${ }^{82}$

\section{Acknowledgments}

Thanks to SENACYT (Secretaría Nacional de Ciencia, Tecnología e Innovación de Panamá) and the Sistema Nacional de Investigación de Panama (SNI) for the award to GCQ. Thanks to the reviewers assigned by the journal for the useful feedback and suggestions.

\section{Disclosure}

There is no conflict of interest in the present work.

\section{References}

1. Zhuo M. Cortical excitation and chronic pain. Trends Neurosci. 2008;31(4):199-207.

2. Xie YF, Huo FQ, Tang JS. Cerebral cortex modulation of pain. Acta Pharmacol Sin. 2009;30(1):31-41.

3. Millan MJ. Descending control of pain. Prog Neurobiol. 2002;66(6): 355-474.

4. Ossipov MH, Dussor GO, Porreca F. Central modulation of pain. J Clin Invest. 2010;120(11):3779-3787.

5. Fields HL, Basbaum AI, Heinricher MM. Central nervous system mechanisms of pain modulation. In McMahon S, Koltzenburg M, editors. Wall and Melzack's Textbook of Pain. 5th ed. Philadelphia: Churchill Livingstone; 2005:125-142.

6. Akil H, Mayer DJ, Liebeskind JC. Antagonism of stimulation-produced analgesia by naloxone, a narcotic antagonist. Science. 1976;191(4230): 961-962.

7. Basbaumm AI, Clanton CH, Fields HL. Opiate and stimulus-produced analgesia: functional anatomy of a medullospinal pathway. Proc Natl Acad Sci U S A. 1976;73(12):4685-4688.

8. Basbaum AI, Clantonm CH, Fields HL. Three bulbospinal pathways from the rostral medulla of the cat: an autoradiographic study of pain modulating systems. J Comp Neurol. 1978;178(2):209-224.

9. Abols IA, Basbaum AI. Afferent connections of the rostral medulla of the cat: a neural substrate for midbrain-medullary interactions in the modulation of pain. J Comp Neurol. 1981;201(2):285-297. 
10. Glazer EJ, Basbaum AI. Immunohistochemical localization of leucineenkephalin in the spinal cord of the cat: enkephalin-containing marginal neurons and pain modulation. J Comp Neurol. 1981;196(3):377-389.

11. Basbaum AI. Descending control of pain transmission: possible serotonergic-enkephalinergic interactions. Adv Exp Med Biol. 1981;133: 177-189.

12. Basbaum AI, Fields HL. Endogenous pain control mechanisms: review and hypothesis. Ann Neurol. 1978;4(5):451-462.

13. Cui M, Feng Y, McAdoo DJ, Willis WD. Periaqueductal gray stimulation-induced inhibition of nociceptive dorsal horn neurons in rats is associated with the release of norepinephrine, serotonin, and amino acids. J Pharmacol Exp Ther. 1999;289(2):868-876.

14. Decety J, Jackson PL. The functional architecture of human empathy. Behav Cogn Neurosci Rev. 2004;3(2):71-100.

15. Jackson PL, Brunet E, Meltzoff AN, Decety J. Empathy examined through the neural mechanisms involved in imagining how I feel versus how you feel pain. Neuropsychologia. 2006;44(5):752-761.

16. Wang $\mathrm{H}, \mathrm{Xu} \mathrm{H}, \mathrm{Wu} \mathrm{LJ}$, et al. Identification of an adenylyl cyclase inhibitor for treating neuropathic and inflammatory pain. Sci Transl Med. 2011;3(65):65ra63.

17. Koga K, Li X, Chen T, Steenland HW, Descalzi G, Zhuo M. In vivo whole-cell patch-clamp recording of sensory synaptic responses of cingulate pyramidal neurons to noxious mechanical stimuli in adult mice. Mol Pain. 2010;6:62.

18. Qu C, King T, Okun A, Lai J, Fields HL, Porreca F. Lesion of the rostral anterior cingulate cortex eliminates the aversiveness of spontaneous neuropathic pain following partial or complete axotomy. Pain. 2011;152(7):1641-1648.

19. Johansen JP, Fields HL, Manning BH. The affective component of pain in rodents: direct evidence for a contribution of the anterior cingulate cortex. Proc Natl Acad Sci U S A. 2001;98(14):8077-8082.

20. Kim SS, Descalzi G, Zhuo M. Investigation of molecular mechanism of chronic pain in the anterior cingulate cortex using genetically engineered mice. Curr Genomics. 2010;11(1):70-76.

21. Wei F, Qiu CS, Kim SJ, et al. Genetic elimination of behavioral sensitization in mice lacking calmodulin-stimulated adenylyl cyclases. Neuron. 2002;36(4):713-726.

22. Lu Y, Zhu L, Gao YJ. Pain-related aversion induces astrocytic reaction and proinflammatory cytokine expression in the anterior cingulate cortex in rats. Brain Res Bull. 2011;84(2):178-182.

23. Wei F, Wang GD, Kerchner GA, et al. Genetic enhancement of inflammatory pain by forebrain NR2B overexpression. Nat Neurosci. 2001;4(2):164-169.

24. Wu LJ, Toyoda H, Zhao MG, et al. Upregulation of forebrain NMDA NR2B receptors contributes to behavioral sensitization after inflammation. J Neurosci. 2005;25(48):11107-11116.

25. Quintero GC, Herrera J, Bethancourt J. Cortical NR2B NMDA subunit antagonism reduces inflammatory pain in male and female rats. J Pain Res. 2011;4:301-308.

26. Li XY, Ko HG, Chen T, et al. Alleviating neuropathic pain hypersensitivity by inhibiting PKMzeta in the anterior cingulate cortex. Science. 2010;330(6009):1400-1404.

27. Li XY, Ko HG, Chen T, Collingridge GL, Kaang BK, Zhuo M. Erasing injury-related cortical synaptic potentiation as a new treatment for chronic pain. J Mol Med (Berl). 2011;89(9):847-855.

28. Ling D, Benardo L, Serrano P, et al. Protein kinase Mzeta is necessary and sufficient for LTP maintenance. Nat Neurosci. 2002;5(4):295-296.

29. Serrano P, Yao Y, Sacktor TC. Persistent phosphorylation by protein kinase Mzeta maintains late-phase long-term potentiation. J Neurosci. 2005;25(8):1979-1984.

30. Hernandez AL, Blace N, Crary JF, et al. Protein kinase M zeta synthesis from a brain mRNA encoding an independent protein kinase $\mathrm{C}$ zeta catalytic domain. Implications for the molecular mechanism of memory. J Biol Chem. 2003;278(41):40305-40316.

31. Volk LJ, Bachman JL, Johnson R, Yu Y, Huganir RL. PKM- $\zeta$ is not required for hippocampal synaptic plasticity, learning and memory. Nature. 2013;493(7432):420-423.
32. Lee AM, Kanter BR, Wang D, et al. Prkcz null mice show normal learning and memory. Nature. 2013;493(7432):416-419.

33. Price TJ, Ghosh S. ZIPping to pain relief: the role (or not) of PKM $\zeta$ in chronic pain. Mol Pain. 2013;9:6.

34. Toyoda H, Zhao MG, Zhuo M. Enhanced quantal release of excitatory transmitter in anterior cingulate cortex of adult mice with chronic pain. Mol Pain. 2009;5:4.

35. Banerjee B, Medda BK, Schmidt J, Lang IM, Sengupta JN, Shaker R. Neuronal plasticity in the cingulate cortex of rats following esophageal acid exposure in early life. Gastroenterology. 2011;141(2):544-552.

36. Wei F, Wang GD, Zhang C, et al. Forebrain overexpression of CaMKII abolishes cingulate long term depression and reduces mechanical allodynia and thermal hyperalgesia. Mol Pain. 2006;2:21.

37. Wang H, Shimizu E, Tang YP, et al. Inducible protein knockout reveals temporal requirement of CaMKII reactivation for memory consolidation in the brain. Proc Natl Acad Sci U S A. 2003;100(7): 4287-4292.

38. Strack S, Choi S, Lovinger DM, Colbran RJ. Translocation of autophosphorylated calcium/calmodulin-dependent protein kinase ii to the postsynaptic density. J Biol Chem. 1997;272(2):13467-13470.

39. Benke TA, Lüthi A, Isaac JT, Collingridge GL. Modulation of AMPA receptor unitary conductance by synaptic activity. Nature. 1998; 393(6687):793-797.

40. Baliki MN, Geha PY, Apkarian AV. Parsing pain perception between nociceptive representation and magnitude estimation. J Neurophysiol. 2009;101(2):875-887.

41. Ogino Y, Nemoto H, Inui K, Saito S, Kakigi R, Goto F. Inner experience of pain: imagination of pain while viewing images showing painful events forms subjective pain representation in human brain. Cereb Cortex. 2007;17(5):1139-1146.

42. Burkey AR, Carstens E, Wenniger JJ, et al. An opioidergic cortical antinociception triggering site in the agranular insular cortex of the rat that contributes to morphine antinociception. J Neurosci. 1996;16(20): $6612-6623$.

43. Jasmin L, Rabkin SD, Granato A, Boudah A, Ohara PT. Analgesia and hyperalgesia from GABA-mediated modulation of the cerebral cortex. Nature. 2003;424(6946):316-320.

44. Coffeen U, Lopez-Avila A, Ortega-Legaspi JM, del Angel R, López-Muñoz FJ, Pellicer F. Dopamine receptors in the anterior insular cortex modulate long-term nociception in the rat. Eur J Pain. 2008;12(5):535-543.

45. Willoch F, Schindler F, Wester HJ, et al. Central poststroke pain and reduced opioid receptor binding within pain processing circuitries: a [11C]diprenorphine PET study. Pain. 2004;108(3):213-220.

46. Zubieta JK, Smith YR, Bueller JA, et al. Regional mu opioid receptor regulation of sensory and affective dimensions of pain. Science. 2001;293(5528):311-315.

47. Xie YF, Wang J, Huo FQ, et al. Mu but not delta and kappa opioid receptor involvement in ventrolateral orbital cortex opioid-evoked antinociception in formalin test rats. Neuroscience. 2004;126(3): 717-726.

48. Maarrawi J, Peyron R, Mertens P, et al. Differential brain opioid receptor availability in central and peripheral neuropathic pain. Pain. 2007;127(1-2):183-194.

49. Burkey AR, Carstens E, Jasmin L. Dopamine reuptake inhibition in the rostral agranular insular cortex produces antinociception. J Neurosci. 1999;19(10):4169-4179.

50. Jasmin L, Burkey AR, Granato A, Ohara PT. Rostral agranular insular cortex and pain areas of the central nervous system: a tract-tracing study in the rat. J Comp Neurol. 2004;468(3):425-440.

51. Tranel D. "Acquired sociopathy": the development of sociopathic behavior following focal brain damage. Prog Exp Pers Psychopathol Res. 1994:285-311.

52. Treede RD, Kenshalo DR, Gracely RH, Jones AK. The cortical representation of pain. Pain. 1999;79(2-3):105-111.

53. Snow PJ, Lumb BM, Cervero F. The representation of prolonged and intense, noxious somatic and visceral stimuli in the ventrolateral orbital cortex of the cat. Pain. 1992;48(1):89-99. 
54. Zhang YQ, Tang JS, Yuan B, Jia H. Inhibitory effects of electrically evoked activation of ventrolateral orbital cortex on the tail-flick reflex are mediated by periaqueductal gray in rats. Pain. 1997;72(1-2): $127-135$.

55. Dang YH, Xing B, Zhao Y, et al. The role of dopamine receptors in ventrolateral orbital cortex-evoked antinociception in a rat formalin test model. Eur J Pharmacol. 2011;657(1-3):97-103.

56. Missale C, Nash SR, Robinson SW, Jaber M, Caron MG. Dopamine receptors: from structure to function. Physiol Rev. 1998;78(1):189-225.

57. Vallone D, Oicetti R, Borrelli E. Structure and function of dopamine receptors. Neurosci Biobehav Rev. 2000;24(1):125-132.

58. Cooper SJ. Anaesthetisation of prefrontal cortex and response to noxious stimulation. Nature. 1975;254(5499):439-440.

59. Zhang S, Tang JS, Yuan B, Jia H. Inhibitory effects of electrical stimulation of ventrolateral orbital cortex on the rat jaw-opening reflex. Brain Res. 1998;813(2):359-366.

60. Baliki M, Al-Amin HA, Atweh SF, et al. Attenuation of neuropathic manifestations by local block of the activities of the ventrolateral orbitofrontal area in the rat. Neuroscience. 2003;120(4):1093-1104.

61. Heinricher MM, Morgan MM, Tortorici V, Fields HL. Disinhibition of off-cells and antinociception produced by an opioid action within the rostral ventromedial medulla. Neuroscience. 1994;63(1):279-288.

62. Paxinos G. The Rat Nervous System. 2nd ed. San Diego: Academic Press; 1995.

63. Shibasaki H. Central mechanisms of pain perception. Suppl Clin Neurophysiol. 2004;57:39-49.

64. Sewards TV, Sewards M. Separate, parallel sensory and hedonic pathways in the mammalian somatosensory system. Brain Res Bull. 2002;58(3):243-260.

65. Kuroda R, Kawao N, Yoshimura H, et al. Secondary somatosensory cortex stimulation facilitates the antinociceptive effect of the NO synthase inhibitor through suppression of spinal nociceptive neurons in the rat. Brain Res. 2001;903(1-2):110-116.

66. Gojyo F, Sugiyo S, Kuroda R, et al. Effects of somatosensory cortical stimulation on expression of c-Fos in rat medullary dorsal horn in response to formalin-induced noxious stimulation. $J$ Neurosci Res. 2002;68(4):479-488.

67. Neto FL, Schadrack J, Platzer S, Zieglgänsberger W, Tölle TR, Castro-Lopes JM. Up-regulation of metabotropic glutamate receptor 3 mRNA expression in the cerebral cortex of monoarthritic rats. JNeurosci Res. 2001;63(4):356-367.

68. Villalba MBJ, Journot L. Pituitary adenylate cyclase-activating polypeptide (PACAP-38) protects cerebellar granule neurons from apoptosis by activating the mitogen activated protein kinase (MAP kinase) pathway. J Neurosci. 1997;17(1):83-90.

69. Sandor K, Kormos V, Botz B, et al. Impaired nocifensive behaviours and mechanical hyperalgesia, but enhanced thermal allodynia in pituitary adenylate cyclase-activating polypeptide deficient mice. Neuropeptides. 2010;44(5):363-371.

70. Rang HP, Ritter JM, Flower RJ. Noradrenergic transmission. In: Rang and Dale's Pharmacology. 6th ed. Philadelphia: Churchill Livingstone; 2007:169-170.

71. Nalepa I, Vetulani J, Borghi V, et al. Changes induced by formalin pain in central alpha1-adrenoceptor density are modulated by adenosine receptor agonists. J Neural Transm. 2010;117(5):549-558.

72. Reis GM, Dias QM, Silveira JW, Del Vecchio F, Garcia-Cairasco N, Prado WA. Antinociceptive effect of stimulating the occipital or retrosplenial cortex in rats. J Pain. 2010;11(10):1015-1026.

73. Vann SD, Aggleton JP, Maguire EA. What does the retrosplenial cortex do? Nat Rev Neurosci. 2009;10(11):792-802.

74. Sanes JN. Primary motor cortex. In: Weiner IB, Craighead WE. The Corsini Encyclopedia of Psychology. Hoboken (NJ): Wiley; 2010.

75. Pagano RL, Fonoff ET, Dale CS, Ballester G, Teixeira MJ, Britto LR. Motor cortex stimulation inhibits thalamic sensory neurons and enhances activity of PAG neurons: possible pathways for antinociception. Pain. 2012;153(12):2359-2369.
76. Pagano RL, Assis DV, Clara JA, et al. Transdural motor cortex stimulation reverses neuropathic pain in rats: a profile of neuronal activation. Eur J Pain. 2011;15(3):268. e1-e14.

77. Tajerian M, Alvarado S, Millecamps M, et al. Peripheral nerve injury is associated with chronic, reversible changes in global DNA methylation in the mouse prefrontal cortex. PLoS One. 2013;8(1):e55259.

78. Jessen K, Mirsky R. Glial cells in the enteric nervous system contain glial fibrillary acidic protein. Nature. 1980;(286):736-737.

79. Xie YF, Zhang S, Chiang CY, Hu JW, Dostrovsky JO, Sessle BJ. Involvement of glia in central sensitization in trigeminal subnucleus caudalis (medullary dorsal horn). Brain Behav Immun. 2007;21(5): 634-641.

80. Kuzumaki N, Narita M, Hareyama N, et al. Chronic pain-induced astrocyte activation in the cingulate cortex with no change in neural or glial differentiation from neural stem cells in mice. Neurosci Lett. 2007;415(1):22-27.

81. Narita M, Kuzumaki N, Kaneko C, et al. Chronic pain-induced emotional dysfunction is associated with astrogliosis due to cortical delta-opioid receptor dysfunction. J Neurochem. 2006;97(5):1369-1378.

82. Watkins L, Maier S. Glia and pain: past, present, and future. In: Merskey H, Loeser JD, Dubner R, editors. The Paths of Pain: 1975-2005. Washington: IASP Press; 2005.

83. Wieseler-Frank J, Maier SF, Watkins LR. Glial activation and pathological pain. Neurochem Int. 2004;45(2-3):389-395.

84. Zhuo M, Wu G, Wu LJ. Neuronal and microglial mechanisms of neuropathic pain. Mol Brain. 2011;4:31.

85. Tsuda M, Inoue K, Salter MW. Neuropathic pain and spinal microglia: a big problem from molecules in "small" glia. Trends Neurosci. 2005;28(2):101-107.

86. González-Scarano F, Baltuch G. Microglia as mediators of inflammatory and degenerative diseases. Ann Rev Neurosci. 1999;22: 219-240.

87. Bruce-Keller AJ. Microglial-neuronal interactions in synaptic damage and recovery. J Neurosci Res. 1999;58(1):191-201.

88. Ji RR, Suter MR. p38 MAPK, microglial signaling, and neuropathic pain. Mol Pain. 2007;3:33.

89. Gosselin RD, Suter MR, Ji RR, Decosterd I. Glial cells and chronic pain. Neuroscientist. 2010;16(5):519-531.

90. Zhang F, Vadakkan KI, Kim SS, Wu LJ, Shang Y, Zhuo M. Selective activation of microglia in spinal cord but not higher cortical regions following nerve injury in adult mouse. Mol Pain. 2008;4:15.

91. Giordano C, Cristino L, Luongo L, et al. TRPV1-dependent and -independent alterations in the limbic cortex of neuropathic mice: impact on glial caspases and pain perception. Cereb Cortex. 2012;22(11):2495-2518.

92. Liauw J, Wu LJ, Zhuo M. Calcium-stimulated adenylyl cyclases required for long-term potentiation in the anterior cingulate cortex. J Neurophysiol. 2005;94(1):878-882.

93. Zhuo M. Central plasticity in pathological pain. Novartis Found Symp. 2004;261:132-145; discussion 145-154.

94. Zhuo M. Targeting neuronal adenylyl cyclase for the treatment of chronic pain. Drug Discov Today. 2012;17(11-12):573-582.

95. Mogil JS, Bailey AL. Sex and gender differences in pain and analgesia. Prog Brain Res. 2010;186:141-157.

96. Greenspan JD, Craft RM, LeResche L, et al. Studying sex and gender differences in pain and analgesia: a consensus report. Pain. 2007; 132 Suppl 1:S26-S45.

97. Mogil JS, Chanda ML. The case for the inclusion of female subjects in basic science studies of pain. Pain. 2005;117(1-2):1-5.

98. Rice AS, Cimino-Brown D, Eisenach JC, et al. Animal models and the prediction of efficacy in clinical trials of analgesic drugs: a critical appraisal and call for uniform reporting standards. Pain. 2008;139(2): 243-247.

99. Khalifa MM, Abdelbaky NA. Synthesis of new imidazolyl acetic acid derivatives with anti-inflammatory and analgesic activities. Arch Pharm Res. 2008;31(4):419-423. 
100. Munoz J, Navarro C, Noriega V, et al. Synergism between COX-3 inhibitors in two animal models of pain. Inflammopharmacology. 2010;18(2):65-71.
101. Lam FF, Ng ES. Substance $\mathrm{P}$ and glutamate receptor antagonists improve the anti-arthritic actions of dexamethasone in rats. $B r J$ Pharmacol. 2010;159(4):958-969.

\section{Publish your work in this journal}

The Journal of Pain Research is an international, peer-reviewed, open access, online journal that welcomes laboratory and clinical findings in the fields of pain research and the prevention and managemen of pain. Original research, reviews, symposium reports, hypothesis formation and commentaries are all considered for publication.

\section{Dovepress}

The manuscript management system is completely online and includes a very quick and fair peer-review system, which is all easy to use. Visit http://www.dovepress.com/testimonials.php to read real quotes from published authors.

\footnotetext{
Submit your manuscript here: http://www.dovepress.com/journal-of-pain-research-journal
} 